\title{
Experimental and Numerical Investigation of Laminar Burning Velocities of Artificial Biogas Under Various Pressure and $\mathrm{CO}_{2}$ Concentration
}

\author{
Willyanto Anggono ${ }^{1,2,3,}{ }^{*}$, Akihiro Hayakawa ${ }^{1}$, Ekenechukwu C. Okafor ${ }^{1}$, and \\ Gabriel Jeremy Gotama ${ }^{2,3}$ \\ ${ }^{1}$ Institute of Fluid Science, Tohoku University, Sendai, Miyagi 980-8577, Japan \\ ${ }^{2}$ Mechanical Engineering Department, Petra Christian University, Jl. Siwalankerto No.121-131, \\ Surabaya 60236, Indonesia \\ ${ }^{3}$ Centre for Sustainable Energy Studies, Petra Christian University, J1. Siwalankerto No.121-131, \\ Surabaya 60236, Indonesia
}

\begin{abstract}
As a renewable and sustainable fuel made from digestion facility, biogas is composed predominantly of methane $\left(\mathrm{CH}_{4}\right)$ and carbon dioxide $\left(\mathrm{CO}_{2}\right) . \mathrm{CO}_{2}$ in biogas strongly affects its combustion characteristics. In order to develop efficient combustors for biogas, fundamental flame characteristics of biogas require extensive investigation. In understanding the influence of $\mathrm{CO}_{2}$ concentration and mixture pressure on biogas combustion, the effects of $\mathrm{CO}_{2}$ concentration on the laminar burning velocity of methane/air mixtures were studied at different pressures. The studies were conducted using both numerical and experimental methods. The experiment was conducted using a constant volume high pressure combustion chamber. The propagating flames were recorded with a high speed digital camera by employing Schlieren photography technique. The numerical simulation was carried by utilizing CHEMKIN-PRO with GRI-Mech 3.0 employed as the chemical kinetics model. The results show that the laminar burning velocity of methane-air mixtures decreased with an increase in $\mathrm{CO}_{2}$ concentration and mixture pressure. Therefore, the burning velocity of biogas mixtures may decrease as the amount of $\mathrm{CO}_{2}$ in the gas increases.
\end{abstract}

Key words: Combustion characteristics, dilution ratio, renewable fuel, sustainable fuel.

\section{Introduction}

Biogas is a renewable fuel which is made from digestion facility and is predominantly composed of methane $\left(\mathrm{CH}_{4}\right)$ and carbon dioxide $\left(\mathrm{CO}_{2}\right)$. The $\mathrm{CO}_{2}$ constituent in biogas significantly affects the combustion characteristics of the fuel. To develop a combustor with efficient use of biogas, optimized power usage, and emissions control, basic flame characteristics of biogas inside the IC engines need to be investigated further.

\footnotetext{
${ }^{*}$ Corresponding author: willy@petra.ac.id
} 
The increase of carbon dioxide concentration in atmosphere is contributed from anthropogenic activity such as utilization of fossil fuel [1]. $\mathrm{CO}_{2}$ contributes to the change of climate because of its greenhouse effect and therefore categorized as greenhouse gases $[2,3]$. Because of that, carbon dioxide emission in large number is the primary source of global warming [4]. In order to find solution to this problem, many researchers have been interested in the study of alternative energy sources to replace fossil fuel [5-7].

As a fuel derived from biodegradable waste, biogas is a renewable energy resource. Biogas is produced from decomposing biomass using bacterial in anaerobic environment [8-10]. The composition of biogas depends on the production procedure and biomass feedstock. Although highly composed of $\mathrm{CO}_{2}$, biogas contributes to small increase of the greenhouse gases concentration in atmosphere because biogas comes from organic matters including plants. Plants have contributed in reducing $\mathrm{CO}_{2}$ concentration on air [2], making biogas a possible carbon neutral energy source [5]. Additional advantage of biogas comes from its viability and low cost. The facilities used to produce biogas are inexpensive and do not require skilled labor to build [11].

Biogas from East Java, Indonesia has high level of carbon dioxide concentration. Since the $\mathrm{CO}_{2}$ content affects the combustion characteristics of biogas, an understanding of the combustion characteristics under various $\mathrm{CO}_{2}$ dilution ratio is required. Furthermore, beside $\mathrm{CO}_{2}$ concentration, the combustion characteristics of fuels are affected by its initial pressure [12-14]. Combustion in internal combustion engines take place under high pressure condition, therefore there is a need for extensive studies regarding the effect of pressure on $\mathrm{CH}_{4} / \mathrm{CO}_{2} /$ Air flames.

The laminar burning velocity is important in developing chemical kinetics mechanisms. It may also be used to characterize various premixed flame phenomena [15]. The laminar burning velocity can be measured from spherically propagating flames by recording the increasing rate of the flame radius with respond to time $[16,17]$. There has been a series of studies on the effects of $\mathrm{CO}_{2}$ and initial mixtures pressure on laminar burning velocity of $\mathrm{CH}_{4}$ [18-23]. Some studies suggested that as the percentage of $\mathrm{CO}_{2}$ in fuel mixture increases, biogas laminar burning velocity decreased [10, 19-22]. Some studies have suggested that compared to other diluents such as $\mathrm{N}_{2}$ (Nitrogen) and $\mathrm{H}_{2}$ (Hydrogen), $\mathrm{CO}_{2}$ has much more significant effect in reducing laminar burning velocity of $\mathrm{CH}_{4}[18,19]$. Halter et al. suggested that two conditions that caused the decrease of laminar burning velocity with an increase in $\mathrm{CO}_{2}$ concentration are $\mathrm{CO}_{2}$ dissociation and the high heat capacity of $\mathrm{CO}_{2}$ [24]. The increase of $\mathrm{CO}_{2}$ leads to the increase of energy required to dissociate the carbon dioxide $\left(\mathrm{CO}_{2}\right)$ into carbon monoxide $(\mathrm{CO})$ and oxygen $\left(\mathrm{O}_{2}\right)$. The presence of $\mathrm{CO}_{2}$ absorbed some of the heat generated from the chemical reactions within the combustion process. There has also been a series of studies on the effect of pressure on the laminar burning velocity of $\mathrm{CH}_{4}[16,21,22,25]$.

Although extensive studies of the combustion characteristics of biogas have been conducted, the effects of high concentration of $\mathrm{CO}_{2}$ up to $70 \%$ has not been investigated. Biogas that was obtained from East Java, Indonesia is found to be high in $\mathrm{CO}_{2}$ content. Therefore, this study aimed to investigate the laminar combustion characteristics thoroughly under various initial mixture pressure of $0.1 \mathrm{MPa}$ and $0.3 \mathrm{MPa}$ and $\mathrm{CO}_{2}$ concentration up to $70 \%$. The initial mixture pressure was varied for $0.1 \mathrm{MPa}$ and $0.3 \mathrm{MPa}$ in order to simulate the condition of an actual combustor working at high pressure condition. Therefore, this investigation discovered the effect of $\mathrm{CO}_{2}$ dilution ratio on laminar combustion characteristics under varied initial mixture pressures. 


\section{Experimental setup and conditions}

This experiment was conducted using the cylindrical constant volume combustion chamber at the Institute of Fluid Science, Tohoku University. The chamber's inner diameter was $270 \mathrm{~mm}$ while its length was $410 \mathrm{~mm}$. The volume of the chamber was roughly around $23 \mathrm{~L}$. The chamber had two adjacent quartz glass windows which allowed for observation of flame propagation in the chamber $[26,27]$. A schematic diagram for this experimental apparatus of this study is shown in Figure 1.

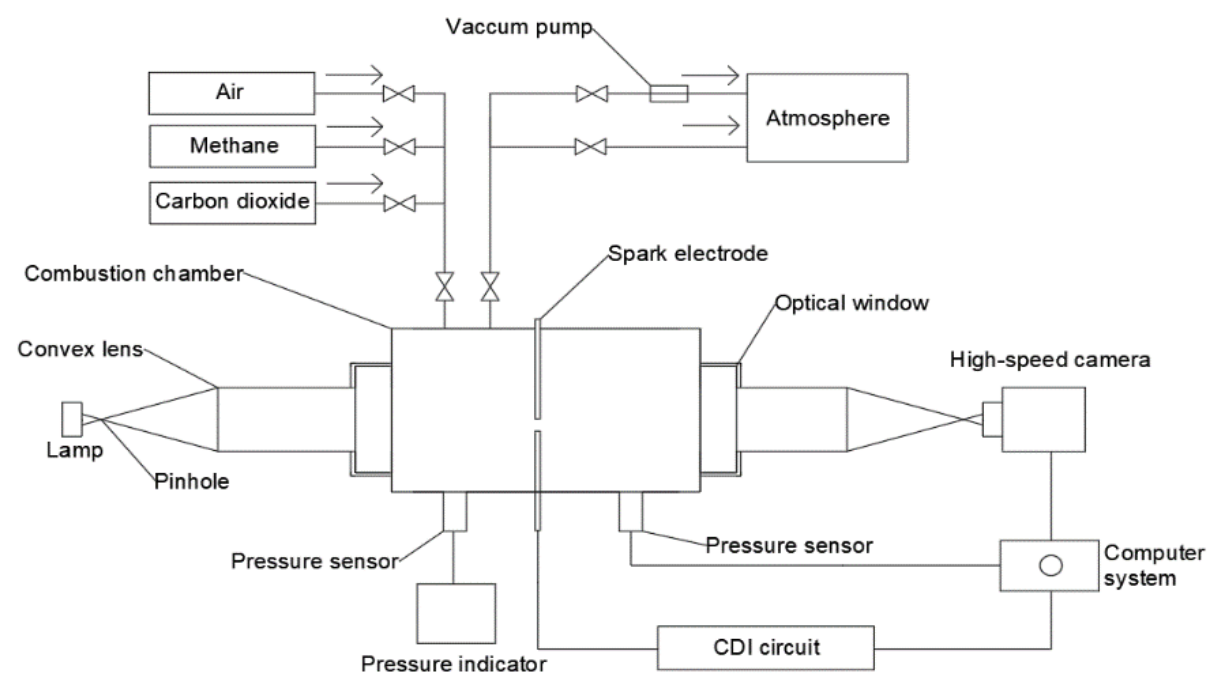

Fig. 1. Schematic of experimental setup.

The fuel-air mixtures were introduced to the chamber and ignited using a pair of spark electrodes. The spark ignition's diameter is $1.5 \mathrm{~mm}$ and the spark gap was set to $2 \mathrm{~mm}$. High speed digital camera (Photron, FASTCAM Mini AX) was used to observe the flame propagation inside the chamber by employing high speed Schlieren photography technique with a continuous light source. The flames can be observed in the chamber through the optical windows up to a diameter of $60 \mathrm{~mm}$. The flames propagated at constant pressure from the time of ignition until their diameter was about $60 \mathrm{~mm}$ [26-28].

Numerical simulations were also performed using a one-dimensional freely propagating laminar flame model of CHEMKIN-PRO. The detailed reaction mechanism, GRI-Mech 3.0 was employed. The initial mixture temperature was set to $298 \mathrm{~K}$. Pressure used was $0.1 \mathrm{MPa}$ and $0.3 \mathrm{MPa}$. In the case of numerical simulation, unstretched laminar burning velocity, $\mathrm{S}_{\mathrm{L}}$, was defined as the velocity at the cold boundary in the computational domain. The burnt gas densities were calculated using the equilibrium calculation of CHEMKINPRO and thermo-physical properties of the mixture such as specific heats, thermal diffusivity, diffusion coefficients were calculated from the same equations employed in CHEMKIN-PRO.

Dry air was used as oxidizer while $\mathrm{CH}_{4}$ with purity of $99.9 \%$ was used as fuel. $\mathrm{CO}_{2}$ with $99.995 \%$ purity was used as diluent. Even though biogas contains nitrogen $\left(\mathrm{N}_{2}\right)$, the quantity is small enough to be neglected. For example, biogas derived from East Java consist of $3 \%$ volume fraction of nitrogen [12]. This value is negligible and thus the $\mathrm{N}_{2}$ content in biogas was not taken into account in this study.

The $\mathrm{CO}_{2}$ concentration in the expressed using Equation (1). In Equation (1), [X] is the molar concentration of species X. An actual biogas has $Z \mathrm{Co}_{2}$ value from 0.3 to 0.5 [11]. In this study, $Z \mathrm{CO}_{2}$ value was varied from 0.3 to 0.7 to holistically investigate the flame 
characteristics for a various biogas of $\mathrm{CO}_{2}$ dilution ratio. Initial mixture pressure, $P_{i}$, was conditioned for $0.1 \mathrm{MPa}$ and $0.3 \mathrm{MPa}$ and initial mixtures temperature was constants at $298 \mathrm{~K}$. At each condition, experiments were conducted for a minimum of five times to bolster the replication of the measurements.

Graph of flame radius as a function of times is displayed in Figure 2. Propagation speed of the flame, $S_{n}$, was obtained from the radius-time record by employing equation (2). The flame stretch rate, $\alpha$, was defined as shown in equation (3). In equation (3), the area of the flame radius is defined as A. For spherically propagating flames, $\alpha$ is obtained using Equation (4) [11-13, 17, 26-28].

$$
\begin{aligned}
& Z_{\mathrm{CO}_{2}}=\frac{\left[\mathrm{CO}_{2}\right]}{\left[\mathrm{CH}_{4}\right]+\left[\mathrm{CO}_{2}\right]} \\
& S_{n}=\frac{d r_{u}}{d t} \\
& \alpha=\frac{d(\ln A)}{d t}=\frac{d A}{A d t} \\
& \alpha=\left(\frac{2}{r_{u}}\right)\left(\frac{d r}{d t}\right)
\end{aligned}
$$

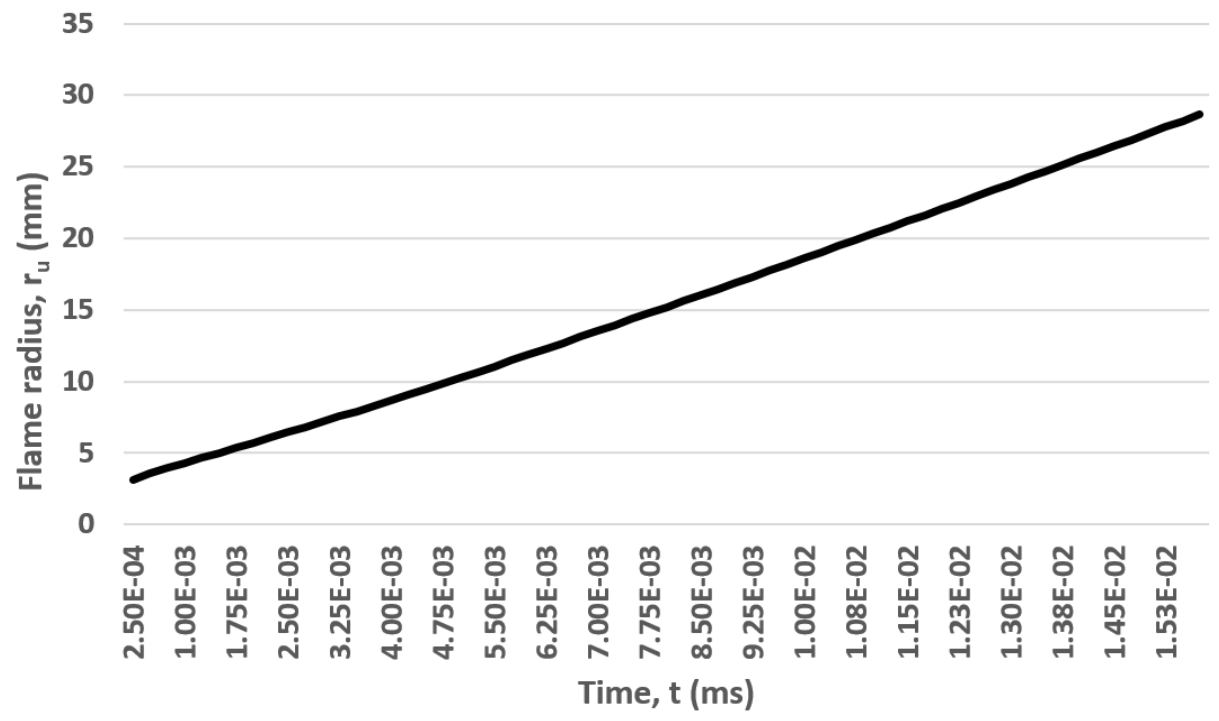

Fig. 2. Flame radius as function of time at $0.1 \mathrm{MPa}$ initial mixture pressure and $\mathrm{Z}_{\mathrm{CO} 2}=0.3$.

Flame speed and total stretch rate may correlate linearly as shown in Figure $3 . \mathrm{L}_{\mathrm{b}}$ is defined at flame radius, $r_{u}$, and their relationship are shown in Equation (5). Unstretched flame speed, $S_{S}$, were assessed from the intercept value of $S_{n}$ when $\alpha=0$ and taking into consideration the connection among the flame stretch and expansion factor. The relationship between flame speed, $\mathrm{S}_{\mathrm{n}}$, and flame stretch rate, $\alpha$, is given in Figure 3. Unstretched laminar burning velocity, $S_{L}$, evaluations were conducted with Equation (6) where $\rho^{u}$ and $\rho^{b}$ are unburnt mixture and burnt gas density, respectively $[5,17,24,28]$.

$$
\begin{aligned}
& S_{n}-S_{s}=L_{b} \alpha \\
& S_{L}=\frac{\rho_{b}}{\rho_{u}} S_{s}
\end{aligned}
$$




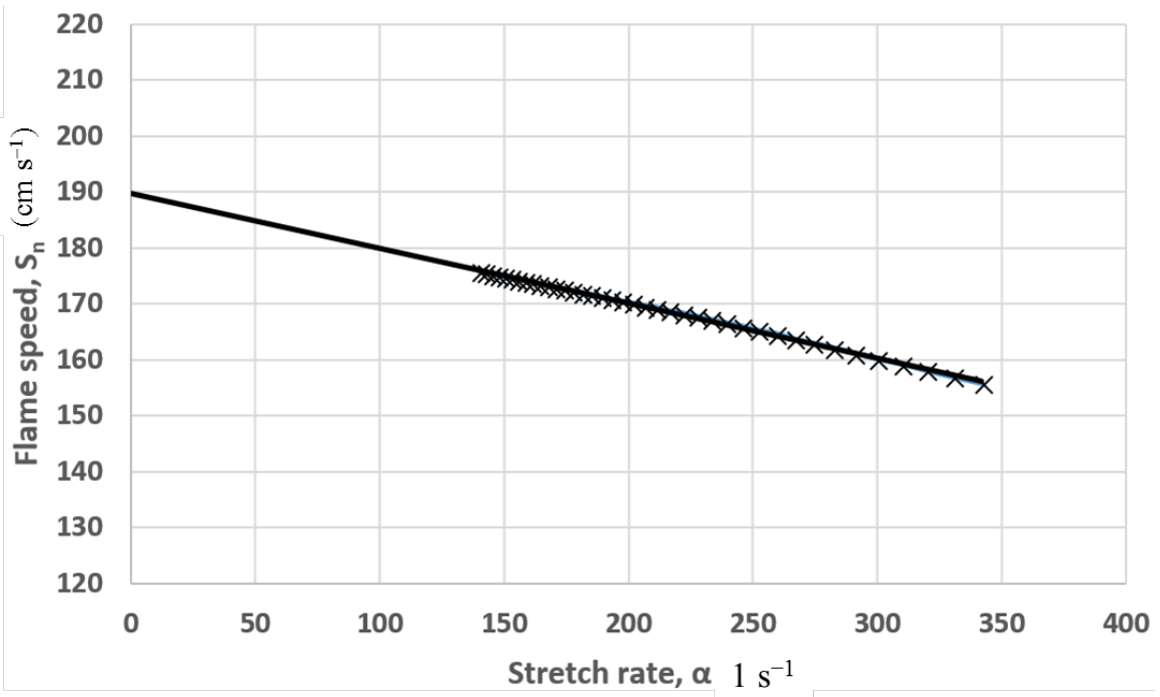

Fig. 3. Flame speed as function of stretch rate at $0.1 \mathrm{MPa}$ initial mixture pressure and $\mathrm{Z}_{\mathrm{CO} 2}=0.3$.

\section{Results and discussion}

Figure 4(a) and Figure 4(b) display the Schlieren images between $2.5 \mathrm{~ms}$ to $10 \mathrm{~ms}$ from ignition for stoichiometric condition at $0.1 \mathrm{MPa}$ and $0.3 \mathrm{MPa}$, respectively. From both figures, it was found that as the $\mathrm{CO}_{2}$ dilution rates and initial mixture pressure are increased, the flame radius decreases. This relationship corresponds to the decrease of laminar burning velocity with the raise of $\mathrm{CO}_{2}$ dilution rates and initial mixture pressures.

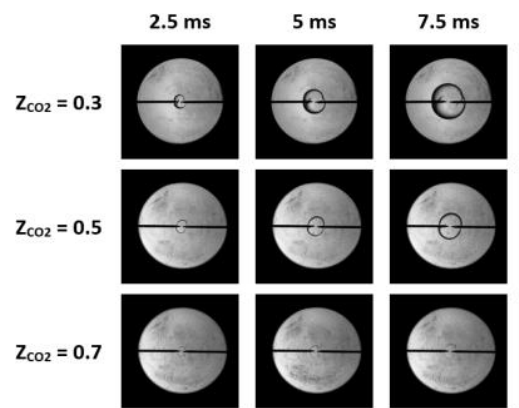

(a)
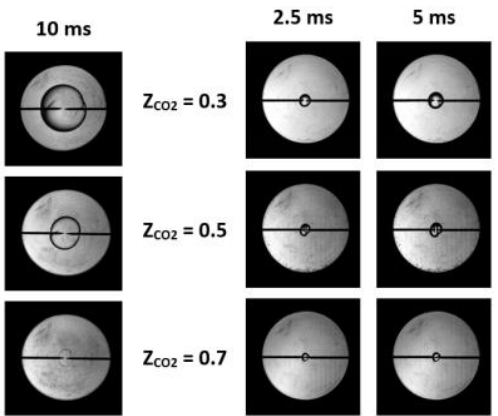

(b)
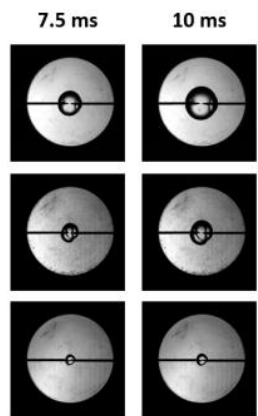

Fig. 4. Schlieren images between $2.5 \mathrm{~ms}$ to $10 \mathrm{~ms}$ after ignition of artificial biogas-air mixtures under various carbon dioxide dilution ratio and initial mixture pressure of (a) $0.1 \mathrm{MPa}$ and (b) $0.3 \mathrm{MPa}$.

Figure 5 displays relation among $\mathrm{CO} 2$ dilution ratio, $Z_{\mathrm{CO} 2}$, and unstretched laminar burning velocity, $\mathrm{S}_{\mathrm{L}}$. In Figure 5, the solid lines show the experimental results while the dashed lines show the outcome of numerical investigation using CHEMKIN-PRO. The specific model of the reaction was achieved numerically using GRI-Mech 3.0. The numerical simulation of laminar burning velocity results was able to predict the result of experimental investigation with small margin of error. The relationship shown in Figure 5 indicates as carbon dioxide concentration and initial mixture pressure value are increased, the laminar burning velocity of the mixture decreases. These results are supported by the 
investigation of Schlieren images provided in Figure 4(a) and Figure 4(b). Many studies have also suggested similar relationship between $\mathrm{CO}_{2}$ concentration and initial mixture pressure toward laminar burning velocity value found in this study $[9,13,16-19,22]$.

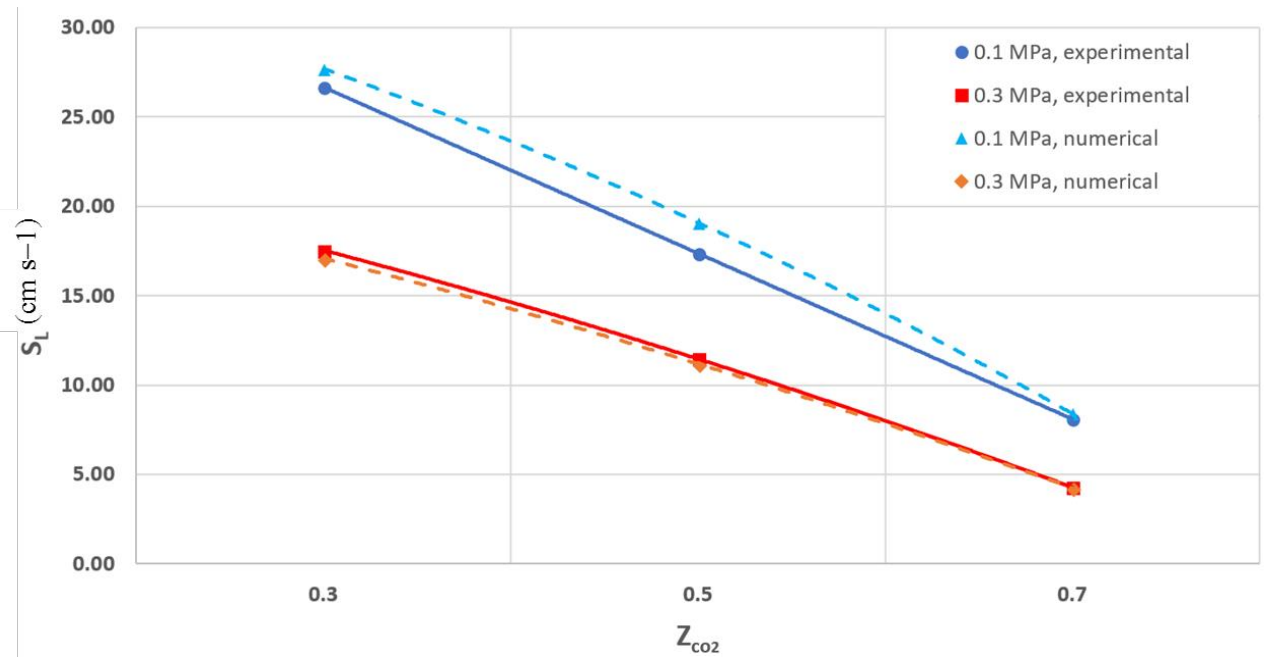

Fig. 5. Laminar burning velocity, $S_{L}$, of artificial biogas-air mixtures under various carbon dioxide dilution ratio and initial mixture pressure.

\section{Conclusion}

From the results of this study, it is found that $\mathrm{CO}_{2}$ concentration and initial mixture pressure are affecting the laminar burning velocity of $\mathrm{CH}_{4} / \mathrm{CO}_{2} /$ Air mixtures at various $\mathrm{CO}_{2}$ concentration and initial pressure. Increase of $\mathrm{CO}_{2}$ concentration and initial mixture pressure in Biogas-Air mixtures lead to the decrease of laminar burning velocity. Both numerical and experimental investigation of laminar burning velocity in $\mathrm{CH}_{4} / \mathrm{CO}_{2} /$ Air mixtures come to the same conclusion with small differences between them. The results of the Schlieren technique support this relationship. As the $\mathrm{CO}_{2}$ concentration and initial mixture pressure are raised, the radius of propagated flame is reduced further.

This study was supported by the Collaborative Research Project of the Institute of Fluid Science, Tohoku University, Japan (Project codes: J17L054 and J18I057) and Petra Christian University, Indonesia. The authors also acknowledge Yuji Naito (Tohoku University) for the help during the experiments.

\section{References}

1. M. Mondal, A. Ghosh, K. Gayen, G. Halder, O.N. Tiwari, J. CO2 Util., 22:317329(2017). https://www.sciencedirect.com/science/article/pii/S2212982017304961

2. Q. Chen, M. Lv, Z. Tang, H. Wang, W. Wei, Y. Sun, J. CO2 Util., 14:1-9(2016). https://www.sciencedirect.com/science/article/pii/S221298201630004X

3. S. Agahzamin, A. Mirvakili, M.R. Rahimpour, J. CO2 Util., 16:157-168(2016). https://www.sciencedirect.com/science/article/pii/S2212982016301561

4. V. Marjanović, M. Milovančević, I. Mladenović, J. CO2 Util., 16:212-217(2016). https://www.sciencedirect.com/science/article/pii/S2212982016301482 
5. W. Anggono, I.N.G. Wardana, M. Lawes, K.J. Hughes, S. Wahyudi, N. Hamidi, J. Appl. Sci. Res., 8,8:4126-4132(2012). https://www.cabdirect.org/cabdirect/abstract/20133032671

6. W. Anggono, F.D. Suprianto, Sutrisno, G.J. Gotama, J. Evander, A.W. Kasrun, ARPN J. Eng. Appl. Sci., 13,3:1080-1084(2018).

https://www.researchgate.net/publication/323470000_Investigation_on biomass briqu ette from Cerbera manghas waste twigs as renewable energy source

7. E.C. Okafor, A. Hayakawa, Y. Nagano, T. Kitagawa, Int. J. Hydro. Energy, 39:24092417(2014). https://kyushu-u.pure.elsevier.com/en/publications/effects-of-hydrogenconcentration-on-premixed-laminar-flames-of-h

8. Y. Kathiraser, Z. Wang, M.L. Ang, L. Mo, Z. Li, U. Oemar, S. Kawi, J. CO2 Util., 19:284-295(2017).

https://www.sciencedirect.com/science/article/pii/S221298201730183X

9. W. Anggono, I.N.G. Wardana, M. Pourkashanian, K. J. Hughes, M. Lawes, N. Hamidi, et al. Experimental and Numerical Simulation on Biogas Flame Propagation Characteristic in Spark Ignition Premixed Combustion. Paper was presented in $3^{\text {rd }}$ International Conference on Engineering and ICT (ICEI2012) (Melaka, Malaysia, 2012). http://fportfolio.petra.ac.id/user_files/98-023/ICEI2012.pdf

10. H.O.B. Nonaka, F.M. Pereira, Fuel, 182:382-390(2016). https://www.sciencedirect.com/science/article/pii/S0016236116304148

11. W. Anggono, I.N.G. Wardana, M. Lawes, K.J. Hughes, IJET 5,6:4980-4987(2013). https://core.ac.uk/download/pdf/19545707.pdf

12. W. Anggono, IJRER., 7,1:304-310(2017). https://www.ijrer.org/ijrer/index.php/ijrer/article/view/5509

13. W. Anggono, I.N.G. Wardana, M. Lawes, K.J. Hughes, S. Wahyudi, N. Hamidi, et al. J. Phys. Conf. Ser., 423:012015(2013). https://core.ac.uk/download/pdf/19661557.pdf

14. E.C. Okafor, M. Toyoda, A. Hayakawa, Y. Nagano, T. Kitagawa, Experimental and Numerical Studies on Burning Velocities and Markstein Numbers of Lean laminar $\mathrm{H}_{2} / \mathrm{CH}_{4} /$ Air flames. Paper was presented in $9^{\text {th }}$ Asia-Pacific Conference on Combustion (Gyeongju, Korea, 2013). https://kyushuu.pure.elsevier.com/en/publications/experimental-and-numerical-studies-on-burningvelocities-and-mark

15. E.C. Okafor, Y. Naito, S. Colson, A. Ichikawa, T. Kudo, A. Hayakawa, H. Kobayashi, Combust. Flame, 187:185-198(2018).

https://www.cheric.org/research/tech/periodicals/view.php?seq=1594581

16. S.Y. Liao, D.M. Jiang, J. Gao, Z.H. Huang, Energy \& Fuels, 18,15:316-326(2004). https://pubs.acs.org/doi/10.1021/ef034036z

17. D. Bradley, R.A. Hicks, M. Lawes, C.G.W. Sheppard, R. Woolley, Combust. Flame, 115,1-2:126-144(1998).

https://www.sciencedirect.com/science/article/abs/pii/S0010218097003490

18. C. Zhang, G. Hu, S. Liao, Q. Cheng, C. Xiang, C. Yuan, Energy, 106:431-442(2016). https://www.sciencedirect.com/science/article/abs/pii/S0360544216303310?via\%3Dih $\underline{\mathrm{ub}}$

19. B. Galmiche, F. Halter, F. Foucher, P. Dagaut, Energy \& Fuels, 25,3:948-954(2011). https://pubs.acs.org/doi/10.1021/ef101482d

20. Y.L. Chan, M.M. Zhu, Z.Z. Zhang, P.F. Liu, D.K. Zhang, Energy Proc., 75:30483053(2015). https://www.sciencedirect.com/science/article/pii/S1876610215013892

21. W. Anggono, I.N.G. Wardana, M. Lawes, K.J. Hughes, S. Wahyudi, N. Hamidi, et al. AIP Conf. Proc., 1717:(2016). https://aip.scitation.org/doi/10.1063/1.4943425

22. M. H. Askari, M. Ashjaee, Energy \& Fuels, 31,3:3196-3205(2017).

https://pubs.acs.org/doi/10.1021/acs.energyfuels.6b02941 
23. H. Kobayashi, H. Hagiwara, H. Kaneko, Y. Ogami, Proc. Combust. Inst., 31:14511458(2007). https://perso.crans.org/epalle/M2/Biblio/CH4CO2/Effects\%20of\%20CO2\%20dilution\%20on\%20turbulent $\% 20$ premixed $\% 20$ flames \%20at $\% 20$ high $\% 20$ pressure $\% 20$ and $\% 20$ high $\% 20$ temperature.pdf

24. F. Halter, F. Foucher, L. Landry, C. Mounaim-Rousselle, Combust. Sci. Tech., 181,6:813-827(2009).

https://www.tandfonline.com/doi/abs/10.1080/00102200902864662

25. N. Hinton, R. Stone, Fuel, 116:743-750(2014).

https://www.sciencedirect.com/science/article/pii/S0016236113008120

26. A. Ichikawa, A. Hayakawa, Y. Kitagawa, K.D.K.A. Somarathne, T. Kudo, H. Kobayashi, Int. J. Hydro. Energy, 40,30:9570-9578(2015). https://www.tib.eu/en/search/id/tema\%3ATEMA20150705594/Laminar-burningvelocity-and-Markstein-length-of/

27. A. Hayakawa, T. Goto, R. Mimoto, Y. Arakawa, T. Kudo, H. Kobayashi, Fuel, 159:98-106(2015).

https://www.sciencedirect.com/science/article/pii/S001623611500650X?via\%3Dihub

28. E.C. Okafor, Y. Nagano, T. Kitagawa, Int. J. Hydro. Energy, 41:6581-6592(2016). https://www.sciencedirect.com/science/article/pii/S0360319915313434?via\%3Dihub 